\section{MEDICAL EDUCATION IN ITALY.}

By F. H. Burton-Brown, M.A., M.B., B.Ch.Oxon., Physician to the British Embassy in Rome; late Professor of Medicine
Punjab University, and Physician to the Mayo Hospital, Lahore. [Cortinued from page 160\%,]

\section{Florence.}

"The Royal Institute of Practical Higher Studies and Postgraduate Study" of Florence is not a University in the technical sense of the word, since it only grants degrees in the four Faculties of the Natural Sciences-Medicine and Surgery, Philosophy, and Pharmaceutical Chemistry. Its medical degrees are, however, of high repute, and the course of instruction here very thorough. There are 15 professors belonging to the Medical Faculty. The professor of physiology is not included in this; the professor of anatomy also teaches histology, the professor of clinical surgery surgical anatomy and operative surgery, and there is an extra chair for diseases of children (medical), while the professor of special surgical pathology gives instruction in the surgical diseases of children. There are 32 privat-docents. In 1900-01 there were 205 students, besides 51 entered for the postgraduate course. In the examinations of the first three years 23 per cent. of the students failed, and in those of the last three years ro per cent. failed; $3^{2}$ entered for the final, of whom none failed.

The official course of study is as follows:

First Year.-Botany, Zoology, Comparative Anatomy and Physiology, Normal Human Anatomy.

Second Year.-Physics, Normal Human Anatomy, General Chemistry, Physiology.

Third Y Year.-Normal Human Anatomy, Pliysiology, General Pathology. Fourth Year.-Pathological Anatomy, Special Demonstrative Medical Pathology, Clinical Instruction in Physical Signs (Medical), Special Surgical Pathology and Diagnosis, Materia Medica, Operative Surgery. Fifth Year.-Pathological Anatomy. Clinical Medicine, Clinical Surgery, Mental Diseases (Clinical), Ophthalmic Surgery, Hygiene.

Sixth Year.-Clinical Medicine, Clinical Surgery, Obstetrics and Gynæcology, Diseas

The great Hospital of Santa Maria Nuova founded in the

thirteenth century by Folco Portinari, the father of Dante's Beatrice, contains most of the medical clinics and laboratories, as well as the library, with most of the current periodicals.

The Anatomieal Institute is provided with a good lecture theatre, dissecting room, practical histology room, and museum. The professor and his assistants have besides rooms for their own private use, and there is a small library of anatomical works attached. The work done by the student consists in attending lectures by the professor five days a week for three years, in dissecting forty "parts" during the three years of study, and in attending practical classes in histology for two years. Demonstrations are also given by the assistants.

General Pathology.-This is Professor Lustig's laboratory, and it is very complete. There are rooms for practical work by the student in bacteriology and pathological chemistry, in which he attends classes during his third year, as well as lectures three days a week. Professor Lustig has prepared large quantities of his plague serum here.

Pathological Anatomy.-This has a good and well-ventilated post-mortem theatre, where lectures are given three times a week to students of the fourth and fifth years; these lectures are systematic, and are intended to cover the most important divisions of the subject. Besides these, special classes are given in pathological histology-a good histological room-three days a week. During the first two months of each year demonstrations are given on the technique of post-mortem examinations twice a week in the theatre, and three days a week there are given demonstrations of post-mortem examinations to the' students taken in classes. There is also a good pathological museum attached, and well-appointed rooms for the professor, Professor Banti, and his assistants, including the usual special library.

Materia medica lectures are given three days a week to students in their fourth year, and there is a suitable museum and rooms for the Professor and his assistants.

Clinical Medicine.-This has an entirely new and magnificent institute which has only just been built; it comprises wards for 70 cases which are selected from the cases admitted to the hospital, and very complete laboratories for clinical bacteriology, histology, and chemistry. There are photographic and $x$-ray rooms. The electric room is at the back of the lecture theatre, so that the keyboard can be pivoted round, and demonstrations in electro-therapeutics given to the students in the theatre. There are also vivaria, and a Pasteur Institute which treats about 50 cases weekly is annexed. The instruction given here comprises daily clinical lectures on cases selected so as to cover each session two or three principal divisions of clinical medicine. One-half of the lecture is taken up with the clinical history and physical signs and symptoms of the cases presented, the other half being concerned with diagnosis and treatment. The Thursday lecture is dedicated to the consideration of physical signs. Every day the assistant professor and the first assistant take classes in the physical signs and symptoms of the cases presented during the lecture of the morning, while the second assistant takes the fourth year students over a similar field. In addition the assistant professor and the assistants, twenty in number take practical classes in bacteriology, histology, and clinical chemistry.

Clinical Surgery occupies an older part of the Hospital, but one which has been well adapted and brought up to date for its purpose. The wards are light and airy, the operating theatre quite modern in its arrangements, and there are good clinical laboratories. The course of instruction comprises clinical lectures five days a week, with especial reference to diagnosis and treatment, operations one day with remarks on surgical therapeutics. Occasionally there are instead of clinical lectures, others on groups of cases which may present especial scientific or therapeutic points. The students assist in turns at the operations. The assistant professor takes classes in minor surgery and bandaging. The students examine the cases entrusted to them in the wards under the supervision of the assistants.

Hygiene. - The laboratory is a very good one, but medical students do not do any practical work therein; they only attend the lectures which are held three times a week during their fifth year. A yearly course is given of practical work for candidates for the Diploma of Public Health, which is required of all health officers.

Practical Operative Surgery.-Classes are held in a suitable set of rooms, and 40 beds in the hospital are set aside for the purposes of teaching clinical and surgical diagnosis: these are attended by students in their fourth year.

Clinic of Diseases of the Skin and Syphilis. - The instruction given comprises three lectures a week, which are partly clinical, and also clinieal demonstrations given by the assistant professor and the assistants, as well as classes in diagnosis. The students are taken over the cases in the wards in groups.

Legal Medicine.-The instruction given comprises lectures three days a week, during which casss of poisoning and others of medico-legal interest admitted are used for purposes of clinical demonstration, as well as such material as may be available from the courts of justice. Post-mortem demonstrations are also given on cases of interest, and practical classes are taken by the assistant professor in the well-appointed laboratory and post-mortem theatre belonging to the Institute.

Obstetric and Gynacological Clinic is opposite the hospital. This is a large and well-appointed institute, and takes in about 900 labours annually, and has 60 gynæcological beds. The course of instruction is given to sixth year men, and comprises five lectures weekly, three of which are clinical. The students assist in turns at the labours, of which there are about 900 yearly, and at the gynæcological operations. There have been 750 laparotomies here during the last six years. The assistant professor holds special classes in practical obstetrics with the dummy. The assistants also take classes in obstetric and gynæcological diagnosis. The students who have assisted at a labour follow up their case in the wards by accomranying the professor or the assistant in his visits. There are also epecial post-graduate classes. In the same building are also given lectures and demonstrations three times a week for students in their fourth year on special medical pathology.

The Laboratories of Chemistry, Physics, and Physiology are contained in another building a little way off. They all possess well-appointed lecture rooms in which lectures and demonstrations are given in each subject three times a week ; for students in their second year in physics and ch('mistry, 
and for students in their second and third years in physiology, but no practical classes are held in these subjects.

In Zoology, Comparative Anatomy, and Physiology, students receive instruction in their first year by means of six lectures a week at the Zoological Institute. Practical classes are also held which, though not compulsory, are recommended by the Faculty of Medicine, and are well attended.

The Botanical Institute.-Lectures and practical classes are given for students in their first year under similar conditions as the preceding.

Mental Diseases.-Instruction in mental diseases is afforded by means of clinical lectures given twice a week at the asylum for students in their fifth zear.

Ophthalmic Surgery.-Instruction, systematic and clinical, is given at the special hospital to students in their fifth year. The ophthalmic hospital is a quarter of a mile from Santa Maria Nuova, and has been lately largely remodelled and enlarged. It is now a very complete hospital with good examination and operating rooms and clinical laboratories. The wards are pleasantly arranged round little cortiles, in which grow palms and flowers, and the hospital looks neat and trim. The instruction given comprises systematic and clinical lectures three times a week for students in their fifth year. Operations, at which the students help in batches of six, are performed on one day a week. The assistant professor and the assistants take classes in ophthalmoscopic examination.

Diseases of Children.--Instruction is afforded by two courses -medical and surgical-which are "complementary," that is, not obligatory but are advised by the Faculty. Practically every student takes them. The Children's Hospital is just outside the city; it was opcned in 1899 , and is built on the pavilion system. The pavilions are connected by a main building, which contains exceedingly good rooms for instruction and research, comprising a very complete operating room with adjoining rooms for sterilisation of operators and material, a neat lecture theatre, very complete clinical laboratories, professor's room (which is a model), and special library and a well-appointed out-patient department. The block of wards for contagious cases is perfectly isolated from the rest of the building, and there is a small building, also isolated, containing a set of small observation wards. The whole hospital is light and airy and cheerful, and in every way good. The instruction given comprises clinical lectures and demonstrations twice a week on cases selected from the wards and out-patient department, and operations once a week.

The instruction given for the privat-docents comprised during the year 1900-I the following courses:

Lectures on embryology twice a week.

Lectures and demonstrations on medical technique twice a week.

Lectures and demonstrations on the physicial signs and symptoms of diseases of the circulatory system.

Bacteriology, lectures, demonstrations, and practical work three time eek (Professor Lustig).

Lectures on special surgical pathology once a week.

Demonstrations on the symptoms of disease of the nervous system once week.

Lectures on the medical diseases of infancy once a week.

Lectures and demonstrations of elementary neurology twice a week.

Lectures on the clinical and pathological differences between diseases

n childhood and adult ilfe.

Lectures on diseases of the digestive system three times a week.

Lectures on pathological bacteriology twice a week (Professor Banti).

Lectures on g7næecological diagnosis twice a week.

Lectures on discases of the eye once a week.

Lectures on the morphology of the vascular system twice a week.

Lectures and demonstrations on medical parasitology.

Lectures on experimental toxicology twice a week.

Lectures on medical ophthalmoscopy The post-graduate course is a yearly one. It comprises
lectures and demonstrations and practical classes by the professors, and is most complete.

\section{Rome.}

The number of medical students in Rome in 1900-I was 64I There were 805 entries for the examinations of the first three years, of which 163 failed (or nearly 20 per cent.), and 1,501 for those of the last three years, of which 120 failed (or 8 per cent.; 128 entered for the M.D.; none failed.

The Medical Faculty consists of 25 professors, the extra chairs being History of Medicine, Diseases of Children, Neuropathology, Traumatology, Diseases of Ear, Clinical
Chemistry and Histology. Professor Magini, of the Faculty of the Natural Sciences, also teaches medical students in general physiology and histology. There are 45 privatdocents. The course of study recommended is :

First Year.-Comparative Anatomy, Human Anatomy, Botany, General Chemistry, Physics, Zoology, Dissections.

Second Year-Human Anatomy, Histology, General Physiology, Organic Chemistry, Experimental Physiology, Dissections, Practical hstoisgy. Practical Phyryct.

Third Year.-Topographical Human Anatomy, Lectures, and Practical Third Year.--Topographical Human Anatomy, Lectures, and Practical Courses, Physiological Technique, Physiological Chemistry and Physics. Fourth Year.-Clinical Surgery, Clinical Medicine, Pathological Fourth Year.-Clinical Surgery, Clinical Medicine, Pathological Medicine, special Demonstrative Medical and Surgical Pathology, Complementary Courses, History of Medicine, Traumatology.

Fifth Year.-Surgical Anatomy and course of operations, Demonstrations in Pathological Anatomy, Clinical Surgery and Medicine, Diseases of the Eye. Experimental Hygiene, Complementary Courses, Diseases of Children.

Sixth Year.-Demonstrations of Pathological Anatomy. Clinical Surgery and Medicine, Clinical Diseases of the Skin and Syphilis, Obstetrics, Clinical Mental Diseases, Complementary Courses, Diseases of the Ear, Neuropathology.

The clinics are at present not very satisfactory; they are scattered over the city and located in old buildings. When, however, the magnificent Policlinico is completed (it is hoped in a year's time) the University will possess in it one of the most complete buildings of the kind in the world.

At present the old hospital of S. Spirito in Sasso, originally founded towards the end of the eighth century by Ina, King of the West Saxons, in the Borgo or borough of the Saxons, is the place where the clinics of medicine, diseases of the eye, of children, of ear, nose, and throat, are held; and although skilfully adapted, yet there is no doubt that they are insufficient to present needs. When the policlinico is opened the old hospital will probably no longer be used as a hospital at all, and its story, extending over 1,200 years, will come to an end, a story so curiously connected with the Saxon race.

The obstetric clinic is at the hospital of S. Giovanni, an even older hospital, attached as it was originally to the palace of an imperial senator. About 1,000 labours take place here annually, each student seeing 12 or 15 .

The surgical clinic is also in an old building, as also are those of diseases of the skin and syphilis, and mental diseases, all somewhat inconvenient in spite of really skilful adaptations.

The instruction given in these clinics is practically the same as the courses given at Turin.

The laboratories of human anatomy, physiology, general pathology, pathological anatomy, experimental pharmacology, general physiology, and zoology are quite modern, and are all situated in a large building, very well arranged and equipped for the needs of a large school and for practical work. The course of instruction given is much the same as at Turin, except that in general physiology which is peculiar (to Rome, and comprises an annual course of lectures and demonstrations three days a week.

The Institute of Hygiene, directed by Professor Celli, is near at hand. It is admirably arranged and equipped. Here an annual course of lectures is given three days a week, and a practical course.

The Institutes of Chemistry, Physics, and Materia Medica are also close to the others, there being a large garden which is common to all, except that of Hygiene. This garden serves as materia medica garden, place for vivaria, etc. These institutes do not directly belong to the Faculty of Medicine; the instruction given in them for medical students comprises courses of lectures, and also, in the two former, courses of practical work.

In all, forty-six free courses are given, no fewer than ten of which have to do with pathology. Many of these are given by men of world-wide celebrity; thus Professor Mazzoni gives a course of clinical yynæcology at the $S$. Giovanni Hospital, where a large number of gynæcological operations are performed annually.

Various courses are also given at other hospitals. Thus, Professor Ghilarducci gives a course on neuropathology at the Hospital of S. Antonio, and a great amount of surgical work is performed at the Consolazione Hospital, where there is a very good operating room under Professor Raffaello Bastianelli. In this way practically the whole of the clinical material 
of the hospitals of Rome, containing some 3,000 beds, is used for teaching purposes, and there is no donbt that this teaching, both in quality and quantity, is extremely good.

\section{BoLOGNA.}

The number of medical students in 1899-1900 was 457. The number of professors is 19, histology being taught by the Professor of Anatomy. There being three extra chairs, orthopædics, diseases of children, and physical therapeutics. There are 30 privat-docents. The number of students who satisfied the examiners for the M.D. was 94 . The need of new laboratories is shown by the falling off in students of late years at this once considered the premier medical school; there were 125 students in their sixth year and only 39 in the first. When the fine laboratories projected are built no doubt the students now attracted by the Universities possessing ampler establishments will again be drawn to Bologna by the fame of its teaching staff.

The course of studies is-

First Year.-Physics, Botany, General Chemistry, Human Anatomy, Histology, Practical Histology, Dissections.

Second Year.-Human Anatomy, Zoology, Comparative Anatomy, and Physiology, Organic Chemistry, Human Physiology, Dissections.

Third Year--Human Anatomy, Human Physiology, Pathological Anatomy, Special Medical Pathology, Special Surgical Pathology.

Fourth Year.-General Pathology, Materia Medica, Pathological Anatomy, Special Medical and Surgical Pathology, Clinical Medicine, Clinical Surgery, Practical Operations.

Fifth Year.-Clinical Medicine, Clinical Surgery, Clinical Mental Diseases, Clinical Diseases of Skin and Syphilis, Legal Medicine, Hygiene, Obstetrics.

Sixth Year.-Clinical Medicine, Clinical Surgery, Clinical!Diseases of Eye, Clinieal Obstetrics, and Gynæcology

The correspondlng examinations held are divided as follows :

First Year.-Physics, Botany, General Chemistry, Histology.

Second Year.-Zcology, Comparative Anatomy and Physiology, Organic Chemistry.

Third Year.-Human Anatomy, Human Physiology.

Fourth Year.-Pathological Anatomy, Meteria Medica, General Pathology, Special Medical and Surgical Pathology, Practical Operations. Fifth Year.-Hygiene, Legal Medicine, Mental Diseases, Clinical Disease of Skin and Syphilis

Sixth Year.-Clinical, Medicine, Surgery, Diseases of Eye, Obstetrics.

Complementary.-Diseases of Children, Orthopædics, Physical Therapeutics.

The biological institutes are old and not well adapted to modern requirements. The museums are rich in specimens, particularly in those of comparative pathology, but are not well catalogued.

All the clinical instruction is given in the University hospital, which is well arranged and equipped, the clinic of Professor Murri being particularly practical in its arrangements. Here great attention is paid to the practical instruction of the student; thus the clinical histories are compiled and registered with great care, and the student seems to have more responsibility than in most medical clinics. The nursing arrangements are especially good, and quite comparable to a large English hospital. The special medical library seemed very good, and it was gratifying certainly to see all the best British authorities represented there. Four courses of special medical pathology are given here by privat docents, so that this clinic is in every way exceptional.

SiENA.

There were 88 medical students in 1898.99 . In the examinations of the first three years $16 \frac{1}{2}$ per cent. failed, about 6 per cent. failed in those of the last three years; 19 presented themselves for the final, all passed.

There are 15 professors, two teaching in two subjects each. The course of study is particularly practical.

First Year.-Zoology, Comparative Anatomy and Physiology, Lectures and Practical Work, Human Anatomy, Dissections, Histology, Practical Histology. Botany.

Second Year.-General Chemistry, Practical Chemistry, Physics, Human Anatomy, Dissections, Histology, Practical Histology, Human Physiology.

Third Year.-Pathology (General), Human Anatomy, Dissections, Histology, Practical Histology, Human Physiology.

Fourth Year.-Surgical Anatomy, Practical Surgical Anatomy. Medical and Surgical (Propedeutics), Pathological Anatomy, Materia Medica (thi course is also recommended to the students of the third year), Clinical Medicine, Clinical Surgery.

Fifth Year.-Pathological Anatomy, Hygiene, Clinical Medicine, Surgery, Eye Diseases, Obstetrics.

Sixth Year.-Practical Surgical Operations, Legal Medicine, Clinical Medicine, Surgery, Mental Diseases, Diseases of Skin and Syphilis.

There are ro free courses, including such subjects as history of medicine, diseases of children, medical ophthalmoseopy, duties of the medical officers of prisons, applied splanchnology, and others.

The University institutions are all modern. The ancient City Hospital was entirely remodelled and transformed into a University Polyclinic-the first opened in Italy-in 1886, under an agreement between the Minister of Public Instruction and the hospital, renewable every nine years. This contains the two general clinics, each of which has depending on it the two special clinics of surgical and medical special pathology and propedeutics. Here are also the other clinics, except that of mental diseases, which is at the large lunatic asylum. There is a very good operating room, lecture theatre, clinical laboratories, and out-patient department. The wards are those of the old hospital, with some fine fourteenth and fifteenth century frescoes on the walls, but have been modernised, new flooring and an excellent system of ventilation having been provided. The obstetric wards are at the top of the building; here about 300 cases of labour are attended yearly, so that each student gets about 12 .

The laboratories of anatomy, pathological anatomy, hygiene, general pathology, and histology are contained in a modern building a little way from the hospital ; they are very completely equipped and admirably arranged. The instruction given is particularly practical. The arrangements of the hygienic laboratory are particularly good.

Pavia.

The number of students in 1900-I was 487 . There were 759 entries for the special examinations of the courses of the first three years. Of these 127 were referred, or about 12 per cent. For those of the last three years there were $1,060,46$ of these were referred, or about $4 \frac{1}{4}$ per cent. ; 75 entered for the Final, and $\mathrm{I}$ failed to pass.

There are 14 professors, surgical anatomy is taught by the professor of surgery, Professor Golgi teaches history and general pathology ; neuropathology is taught by the Professor of Mental Diseases. There are 27 privat-docents, who give 27 courses, comprising special parts of the official courses, and also some others, such as human parasitology, diseases of children, and diseases of the ear, nose, and throat.

The official courses are :

First Year.-Botany, Zoology, Human Anatomy, General Chemistry. Second Year.-Physics, Comparative Anatomy and Physiology, Human Anatomy, Physiology, Histology, Dissections.

Third Year.-Physiology, General Pathology, Materia Mediea.

Fourth Year.-Medical Pathology (lectures and practical work), Surgica Pathology, Pathological Anatomy, Practical Operations, Hygiene, Medical and Surgical "Propedeutics," Medical Histology and Chemistry (Complementary).

Fifth Year.-Practical Pathological Anatomy, Medical Pathology, Clincal Medicine, Clinical Surgery, Lectures on Obstetrics, Diseases of the Eye (Clinical and Practical Work), Legal Medicine.

Sixth Year.-Clinical Medicine and Ward Work. Clinical Surgery and Ward Work, Clinical Obstetries and Gynæcology, Clinical Diseases of the Skin and Syphilis, Mental Diseases and Neuropathology.

The laboratories are contained in the Biological Institution, a fine and well-equipped building; those belonging to Professor Golgi and Professor Monti are particularly good. The University Hospital is well arranged, and possesses good clinical laboratories, lecture and operating theatre, postmortem theatre, etc.

\section{Parma.}

There were 181 medical students in $1900-1901$ and 38 passed the final examination. There are fourteen professors, three teachers, two subjects each.

The official course of study is as follows :

First Year.-Botany, Zoology, Comparative Anatomy and Physiology. Human Anatomy, Histology, Practical Histology.

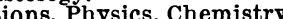
Third Year.-Human Anatomy, Dissections, Physiology, General Pathology, Materia Medica.

Fourth Year. - Surotical Anatomy, Clinical Pharmacology, Speeial Medical and Surgical Pathology and "Propedeutics," Operative Surgery, Pathological Anatomy.

Fifth Year-Clinical Medicine and Surgery, Clinical Diseases of the Eye Hygiene, Experimental Legal Medicine, Practical Pathological Anatomy. Obstetrics and Gynæcology.

Sixth Year.-Clinical, Medicine, Surgery, Diseases of Skin and Syphilis, Mental Diseases, Obstetrics and Gynæcology (practical)

The institutes and clinics are partly old, but, on the whole, made fairly suitable for modern needs by adaptations, and partly new, well built, and equipped. Thus most of the laboratories are in an old Jesuit convent, which has had to be 
considerably altered ; they are, however, fairly well equipped, though the reoms for practical work are only suited for small classes. Much attention is, however, paid to practical work in all subjects. The two general clinics and their corresponding "propedeutic" clinics are situated in a new building in the grounds of the city hospital, as is also the clinic of diseases of the eye. This is quite modern, and well equipped, thoagh somewhat small. This defect it is hoped to remedy shortly by the building of a new clinic to contain the surgical division. The wards here have the privilege of choosing their cases from the cases admitted, and, what is quite exceptional, of returning them to the general wards as soon as they have been used for teaching purposes. A newly-built children's hospital also, which is used for teaching purposes, is attached to the city hospital. The clinic for diseas as of the skin and syphilis is a new building, and is very well arranged, particularly for teaching purposes. It has plenty of room for the students, as well as good research rooms, room for endoscopic work, wards, out-patient's department, photographic room, and library.

The Lying-in Hospital takes in over 200 cases of labour yearly, and possesses a good lying-in room, and, what is somewhat unusual, a room for students on dity to sleep in. There is a good operating room, and wards for gynæcological cases.

There is a large lunatic asylum some way out of the city where instruction is given in mental diseases. Both teachers and students are conveyed thereto at the public expense.

\section{Palermo.}

The number of students in $1897-98$ was 316 . Twelve per cent. failed in the examinations of the first three years, and about 4 per cent. in those of the last three. Fifty-nine entered for the final examination, and all passed. There are 17 professors - the normal number. and 29 privat-docents.

The course of study recommended is :

First Year.-Physics, Chemistry, Iruman Anatomy, Histology.

Second Year.-Human Anatomy, Dissections, Physiology, Botany, Zonlogy, Comparative Anatomy, and Physiology.

Third Year-Human Anatomy, Dissections, Materia Medica-lectures and prac

Fourth Year.-Clinical Medicine and Surgery, Special Medical and Surgical Pathology, Pathological Anatomy

Fifth Year.-Clinical Medicine and Surgery, Clinical Diseases of the Eye end Obstetrics, Surgical Anatomy, Pdthological Anatomy.

Six!h Year-Clinical Medicine and Surgery, Clinical Mental Diseases, Diseases of the Skin and Syphilis, Legal Medicine, Hygiene.

The laboratories and clinies of the uuiversity are old and unworthy of its reputation as the premier university of Sicily. It is intended to replace them by entirely new institutions at an early date.

\section{NAPLES.}

There were 1,889 medical students in 1894.1895. About 18 per cent. were rejected at both preliminary and later examinations; 282 presented themselves for the final, of whom 1 failed. There are 25 professors, the 8 extra chairs being in practical pathological anatomy, neuropathology, laryngology, physiological chemistry, diseases of the ear and nose, orthopædics, diseases of children, and second clinical medicine. There are considerably more than the usual number of assistants, corresponding to the size of the school, and 128 privatdocents.

The course of studies recommended by the Faculty is very explicitly set out. The official courses are much the same as those of Pavia, but in addition the Faculty strongly recommends the following free courses :

First Year. - Practical Chemistry, Practical Physics, Dissections 2 courses nnly can be taken).

Second Yenr. - Practical E nbryology, Practical Histology, Practical Comparative Anatomy and Pbysiology, Microscopic Anatomy (2 courses only

Third Year.-Practical Physiology, Practical Physiological Chemistry. Fourth Year--Pathologica] Histology, Neuropathology.

Fifth and Sixth Years.-One of the complementary professorial courses.

There are 158 free courses, so that the student has plenty of ch jice.

Genoa.

The numbers of medical students in $1897-98$ was 355 , the latest figures to which I have had access. The number of entries for the examinations of the last three years was 609 , of whom 94 failed, or 16 per cent. The corresponding figures for the last three years were 853 and 54 , or 6 per cent. Fifty entered for the final, and 1 failed. There are 19 professors the professor of anatomy teaches in addition histology, the three extra chairs being in diseases of the ear and throat, physiological chemistry, and dental surgery.

The course of study is much the same as that of Florence. There is a particularly large lying-in hospital, with wards for gynæcological cases, taking over 1,000 cases of labour vearly.

Padua.

The number of students in 1897.98 was 389 ; 12 per cent. failed in the examinations of the first three years, and i 1 per cent. in those of the last three; 73 entered for the final and 2 failed. There are 18 professors, including a chair for diseases of children. There are 24 privat-docents. The course of study recommended is practically the same as that of Bologna. There were 32 courses given by the privat-docents. The Anatomical Institute comprises what is said to be one of the finest collections of wax models in the world.

In conclusion, there is no doubt that a vast change has come over medical teaching at the Italian universities during the last thirty, and especially the last fifteen, years. New laboratories and clinics have been built and are being built everywhere, and method and order introduced. The university authorities appear to be animated by the desire to give a sound ecientific and practical training to their students; and, indeed, the feelings which $I$ have experienced in visiting them may be best expressed by the lines : For. when such light is in the world, we share, All of us, all the rays thereof that shine.

\section{REORGANISATION OF THE ARMY MEDICAL SERVICE.}

EACH foreign mail-especially from India and South Africa-brings us a large number of letters from medical officers, offering, of course, altogether independent criticism (for no collusion could be suggested in places so widely apart) and mostly destructive of the the scheme embodied in the report of the Reorganisation Committee. The unanimity with which leading features of the scheme meet with strong condemnation is very striking and can be no mere coincidence. It proves that, in the opinion of those best fitted to know, it would have disastrous consequences to the present and future of the Army Medical Corps should it be forced on the service in its first crude form.

One of the letters received within the last few days is of particular interest, because it is stated to embody the views of nine officers of the corps of from 7 to 16 years service. After a prelude, it reviews the several clauses of the Reorganisation report, as follows:

Although we consider the scheme contains many good points, as a whole it is fantastic and unworkable. We who for many years have been working under existing warrants consider our rights under the scheme seriously jeopardised; it will not, moreover, attract recruits to the corps. The whole matter should be rediscussed by a committee of car the medical sponsible Advisory Board

Paragraphs is to 18 . - The Directo:-General alone should have promotion in his hands.

Paragraph 25.-We feel strongly that Netley should be retained and strengthened, and, instead of a proposed farcical, there should be a real four months probation there for lieutenants, followed by a two-months course at Aldershot.

Pals is mot likely to be worth retaining, and should be dismissed.

Paris, an friction.

Paragraph 30 requires explanation. Anything like a post.graduate course comes too early in a lieutenant's career, aud, if he be kept a for study purposin

Paragraph on to good candiTates and i $3 \mathrm{r}$ to 33 . - This exa indifferent. So many examinations will dates and impracticable for ted with so heavy risks in case of failure, and prove most deterrent, coupled through mere marks.

Paragraph 34 means that no young officer cau be available for foreign service, which is absurd and unworkable.

Paragraph 36 .-Six montlus for real study should be given at the end of Paragraph 36 . - Six montles fice
the first tour of foreign service.

Pdragraphs 37 to 38.-Special and first-class certificates should carr for accelerated promotion, only six and twelve months not twelve and eighteen. The second and third examinations have mucl of a chance element, are quite unnecessary, and must breed grievous dissatisfaction. Any competition by a supersession of seniors is entirely new to the army. 